\title{
Removal Elements from an Industrial Wastewater of Refinery at Different Temperatures using CNTs
}

\author{
H. I. Abdulgafour ${ }^{1}$, F. M. Mohammed ${ }^{2}$, M. A. Abdul-Majeed ${ }^{3}$ \\ ${ }^{1,2,3}$ Ministry of Science and Technology, Baghdad- Iraq
}

\begin{abstract}
This study describes the adsorption capability and treatment efficiency of Al-Dora refinery wastewater treatment unit using multiwall carbon nanotubes (MWCNTs). A divalent heavy metal ions (cobalt, lead, copper), oil content, total suspended solids (TSS), nitrate oxides $\left(\mathrm{NO}_{3}, \mathrm{NO}_{2}\right)$, chemical oxygen demand (COD) and trihalomethanes (THMs) were selected as a field case study in this research. The adsorption characteristics of elements on the adsorption behaviour towards MWCNTs from wastewater of Al- Dora refinery at different temperatures $\left(25,30,40,50,60,70^{\circ} \mathrm{C}\right)$ were studied. The higher adsorption capacity was found to be around $11 \pm 0.1$ mg $g^{\square}$ for oil and THMs at $50^{\circ} \mathrm{C}$. For heavy metals removal cobalt was found higher percentage removal compared to other ions (lead and copper) which is about $60 \%$, while the percentage removal of COD, nitrate and TSS was 97\%, 83\% and 73\%, respectively. This research approved the high efficiency and unique properties of the carbon-based nanomaterials as promising industrial wastewater treatment technology.
\end{abstract}

Keywords: Carbon nanotubes, Adsorption, Heavy metal ions, wastewater treatment technology

\section{Introduction}

Nanotechnology refers broadly to using materials structures with nanoscale dimensions, usually ranging from 1 to 100 nanometers $(\mathrm{nm})$. The basic structures of nanotechnology include nanoparticles or nanocrystals, nanolayers, and nanotubes. Nanostructures, such as silicon nanowires that detect $\mathrm{pH}$, carbon nanotubes, small organic molecules, and biomolecules are examples of nanoscale materials, devices, and circuits that could be used for pollutant sensing, prevention, and treatment [1].

Water contamination is one of the major problems which the world is facing today, and is not only effect environment and human health, but it has also impacts on economic and social costs. Nanotechnology has also proved to be one of the finest and advance ways for waste water treatment. There are various reasons behind the success of nanotechnology and scientists are still working on further enhancement of its usage. Various classes of nanomaterials are also proved to be efficient for water treatment like nanostructured catalytic membranes, nanosorbents, nanocatalysts, bioactive nanoparticles, biomimetic membrane metal-containing nanoparticles, carbonaceous nanomaterials, zeolites, dendrimers and molecularly imprinted polymers [2].

Nanoparticles have a great potential to be used in waste water treatment. Its unique characteristic of having high surface area can be used efficiently for removing toxic metal ions, disease causing microbes, organic and inorganic solutes from water. On the other hand, the nanoparticles have very high absorbing, interacting and reacting capabilities due to its small size with high proportion of atoms at surface. Nanoparticles have great advantage of treating water in depths and any location which is generally left out by other conventional technologies. Since water treatment using nanoparticles has high technology demand, its usage cost should be managed according to existing competition in market [3].
The effects of heavy metals such as lead, mercury, copper, zinc and cadmium in water have been a major preoccupation for many years because of their toxicity towards human health. Several processes have been used and developed over the years to remove metal ions, such as chemical precipitation, reverse osmosis, electrolytic recovery, ion exchange or adsorption [4].

Carbon nanotubes (CNTs), a new form of carbon, are attracting researchers' great interest due to their exceptional mechanical properties [5], unique electrical property [6], highly chemical stability and large specific surface area since their discovery [7]. Their hollow and layered nanosized structures make them a good candidate as adsorbers. Recently, MWCNTs have been characterized as efficient adsorbents with a capacity that surpasses that of activated carbon [8, 9]. Considerable attention has focused on adsorption by CNTs of contaminants such as dioxin [10], $\mathrm{Zn}^{2+}$ [11], $\mathrm{Pb}^{2+}$ [12], $\mathrm{Cd}^{2+}, \mathrm{Cu}^{2+}$ [13], trihalomethanes [14], cadmium [15], and Ni(II) [16]. The hexagonal arrays of carbon atoms in graphite sheets of CNTs surface have strong interactions with other molecules or atoms. The study of adsorption properties of carbon nanotubes is important in both fundamental and practical point of view. In this work, the analytical potential of CNTs as an adsorbent at different temperatures for elements removal such as the oil, TSS, COD and THM concentrations on the adsorption behaviour towards CNTs from waste water of Al- Dora refinery had been studied. A part from this study, the additional ion concentrations of the selective heavy metal like $\mathrm{Cu}, \mathrm{Pb}$, and Co from industrial wastewater of Al- Dora refinery and on the adsorption behaviour was examined.

\section{Materials and Method}

Wastewater from Al- Dora refinery have been treatment using multi walled carbon Nanotubes (MWCNTs, purity > 95\%, O.D (outside diameter): 5-15 nm, I.D (inside diameter): 3-5 nm, length: $\sim 50 \mu \mathrm{m}$, Us Research Nanomaterials Inc., 


\section{International Journal of Science and Research (IJSR) \\ ISSN (Online): 2319-7064}

Index Copernicus Value (2013): 6.14 | Impact Factor (2014): 5.611

USA). Figure 1 shows the TEM image of as grown carbon nanotubes.

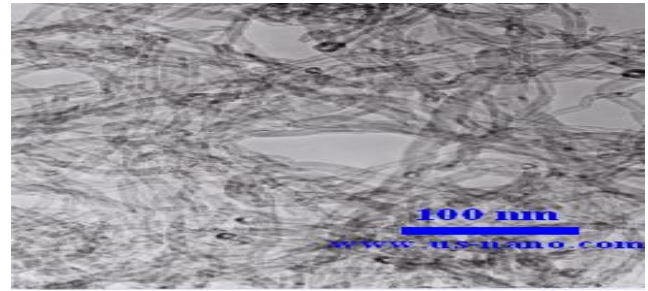

Figure 1: TEM image of as-grown carbon nanotubes (Us Research Nanomaterials Inc., USA).

In this work, one gram of activate carbon nanotubes (MWCNTs) was soaked in $50 \mathrm{~mL}$ of $\mathrm{HNO}_{3}$ for $12 \mathrm{~h}$ at room temperature. The samples were washed with deionized water until the neutral $(\mathrm{pH}=7)$ as well as the solution was filtered through a $0.45 \mu \mathrm{m}$ membrane filter [13].

In adsorption experiments $50 \mathrm{mg}$ of MWCNTs were mixed with $10 \mathrm{~mL}$ of wastewater from Al-Dora refinery under ultrasonication technique. Removal of heavy metal ions and organic compounds from Al- Dora refinery waste water were investigated. On the other hand, the adsorption behavior from wastewater solution with different heavy metal ions concentrations removal includes $\mathrm{Cu}, \mathrm{Pb}$, and $\mathrm{Co}$ was examined by Atomic Absorption Spectrometry (AAS, Nova 400; Analytic Jena, Germany). The nanomaterials suspension was sonicated at different temperatures such as $25,30,40$, $50,60,70^{\circ} \mathrm{C}$ for $1 \mathrm{~h}$ using a bath sonicator to ensure homogeneous nano-particle dispersion. After the suspensions were sonicated for $1 \mathrm{~h}$ at room temperature, they were filtered through $0.45 \mu \mathrm{m}$ membrane filters. Finally, the amounts of metal ions adsorbed on MWCNTs were measured and calculated as the difference between initial and final concentration by an atomic absorption spectrophotometer as will as the oil content, $\mathrm{NO}_{3}, \mathrm{NO}_{2}$, THM, COD and TSS concentrations were tested by HORIBA/ Japan, UV/visible spectrophotometer (Cecil/ UK), gas chromatography (GC, DANI/ Italy), (Dr 5000 color meter/Hatch) and Weighted method respectively. Figure 2 shows the schematic diagram of treatment process by MWCNTs.

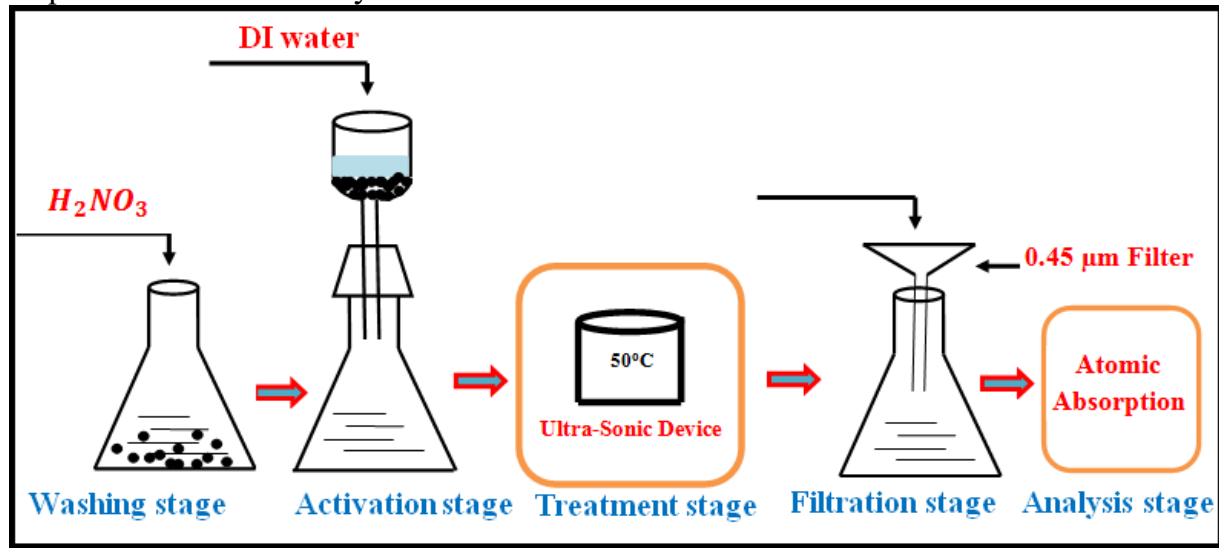

Figure 2: The schematic diagram of treatment process by MWCNTs.

\section{Results and Discussion}

The chemical and thermal treatment processing could have great impact on the adsorption capability of MWCNTs for metal ions removal, because the performance of carbon materials is mainly determined by the nature and concentration of the surface functional groups. Gas phase oxidation of activated carbon increases mainly the concentration of hydroxyl and carbonyl surface groups, while oxidation in the liquid phase increase particularly the content of carboxylic acids [12]. Oxidation of MWCNTs with nitric acid is an effective method to remove the amorphous carbon, carbon black and carbon particles introduced by their preparation process [11]. It is known that oxidation of carbon surface can offer not only a more hydrophilic surface structure, but also a larger number of oxygen-containing functional groups, which increase the ion-exchange capability of carbon material. Nitric acid treatment reduced these groups and additionally creates the new acidic groups, which dominate the surface charge of the carbon nanotubes. Furthermore, it has been reported that the as-grown MWCNTs have weak adsorption capability compared with activated MWCNTs by concentrated nitric acid; so our experiments were carried out only under acidic condition
[10]. Samples of wastewater from Al- Dora refinery have been characterized and treated by using activated MWCNTs. Table. 1 and figure 3 show the results of the treatment process for removal elements such as the oil, $\mathrm{NO}_{3}, \mathrm{NO}_{2}$, THM, COD, and TSS from wastewater of Al- Dora refinery at different temperatures. The percentage removal for these elements was calculated from equation (1).

$$
\% \text { removal }=\frac{C_{i}-C_{f}}{C_{i}} \times 100
$$

where $C_{i}$ and $C_{f}$ are the concentrations before and after treatment $(\mathrm{mg} / \mathrm{L})$ of the contaminants in the solution. It can be seen from Table 1 the percentage removal of contaminated wastewater for the oil and THMs were $100 \%$. In addition, the effect of some metals ions concentrations such as lead, copper and cadmium on the adsorption behavior of the syntheses wastewater was studied. The initial metal concentration was increased from 5 to $25 \mathrm{mg} / \mathrm{L}$, while $\mathrm{pH}$ of all solutions was fixed at 7 also the temperatures were fixed $50{ }^{\circ} \mathrm{C}$. It could be seen that the removal of heavy metals by activated $\mathrm{CNTs}$ of $\mathrm{Pb}$ and $\mathrm{Co}$ was higher than $\mathrm{Cu}$ depend on the surface charge of the adsorbent, degree of ionization, and speciation of the adsorbate $[10,11]$.

\section{Volume 4 Issue 12, December 2015}




\section{International Journal of Science and Research (IJSR) \\ ISSN (Online): 2319-7064}

Index Copernicus Value (2013): 6.14 | Impact Factor (2014): 5.611

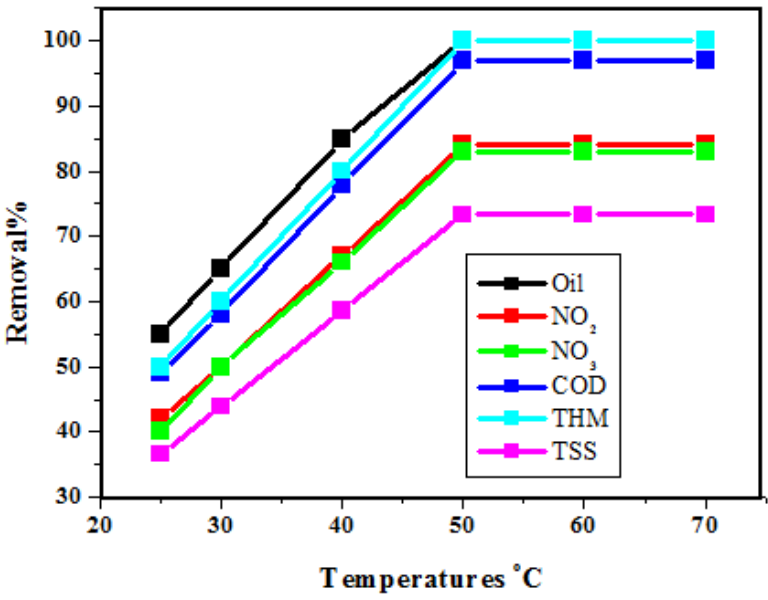

Figure 3: The removal elements by MWCNTs from wastewater of Al-Dora refinery at different temperatures.

Table 1: The removal elements from wastewater of Al-Dora refinery at different temperatures

\begin{tabular}{|c|c|c|c|c|c|c|}
\hline Temperatures & $\begin{array}{c}\text { removal \% } \\
\text { Oil }\end{array}$ & $\begin{array}{c}\text { removal \% } \\
\mathrm{NO}_{2}\end{array}$ & $\begin{array}{c}\text { removal \% } \\
\mathrm{NO}_{3}\end{array}$ & $\begin{array}{c}\text { removal \% } \\
\text { COD }\end{array}$ & $\begin{array}{c}\text { removal \% } \\
\text { THM }\end{array}$ & $\begin{array}{c}\text { removal \% } \\
\text { TSS }\end{array}$ \\
\hline 25 & 55 & 42 & 40 & 49 & 50 & 36.6 \\
\hline 30 & 65 & 50 & 50 & 58 & 60 & 43.9 \\
\hline 40 & 80 & 67 & 66 & 78 & 80 & 58.6 \\
\hline 50 & 100 & 84 & 83 & 97 & 100 & 73.3 \\
\hline 60 & 100 & 84 & 83 & 97 & 100 & 73.3 \\
\hline 70 & 100 & 84 & 83 & 97 & 100 & 73.3 \\
\hline
\end{tabular}

The percentage removal was found $[17,12]$ to increase gradually with increasing $\mathrm{pH}$ and reaches an optimum value of ( $\mathrm{pH}$ 7.0) for $\mathrm{Pb}(\mathrm{II}), \mathrm{Cu}(\mathrm{II})$, and for $\mathrm{Hg}(\mathrm{II})$. As mentioned above, our study assumes that the process tends towards neutral $\mathrm{pH}(7)$ under all conditions. The metal concentration of the syntheses solutions was determined by atomic absorption spectrophotometer. The adsorption capacity $q$ ( $m g / g$ CNTs) was obtained as follows:

$$
q=\left[\left(C_{i}-C_{f}\right) V / m\right]
$$

Where $C_{i}$ and $C_{f}$ are the initial and final concentrations $(\mathrm{mg} / \mathrm{L})$ of metal ion in the syntheses solution, respectively, $(V)$ the volume of metal ion solution and $(m)$ is the weight of MWCNTs.

On the other hand, the adsorption capacity is an important factor because it determines how much sorbent is required for quantitative enrichment of the analyzed from a given solution. Figure 4 shows the adsorption capacity of $\mathrm{Co}, \mathrm{Cu}$, and $\mathrm{Pb}$ at their initial concentration range of 5-25 $\mathrm{mg} / \mathrm{L}$ with activated MWCNTs at $50{ }^{\circ} \mathrm{C}$. It could be seen from Figure 4, the Co ions are more favorably adsorbed on MWCNTs and the adsorption capacity of Co was $3 \mathrm{mg} / \mathrm{g}$ at an equilibrium concentration of $250 \mathrm{mg} / \mathrm{L}$, while the adsorption capacity for $\mathrm{Pb}$ and $\mathrm{Cu}$ were 2.8 and $1.7 \mathrm{mg} / \mathrm{g}$, respectively, as shown in Table 2. Under the condition (pH7), the adsorption capabilities of CNTs for these three heavy metal ions are in the order of $\mathrm{Co}>\mathrm{Pb}>\mathrm{Cu}$. Also, the mean removal efficiencies of $60 \%$ for $\mathrm{Co}, 56 \%$ for $\mathrm{Pb}$, and $35 \%$ for $\mathrm{Cu}$ elements had been observed. Thus, a carbon nanotube has good adsorption properties and high capacity for Co and can be applied for the preconcentration and purification of these elements in aqueous solutions containing other metals.

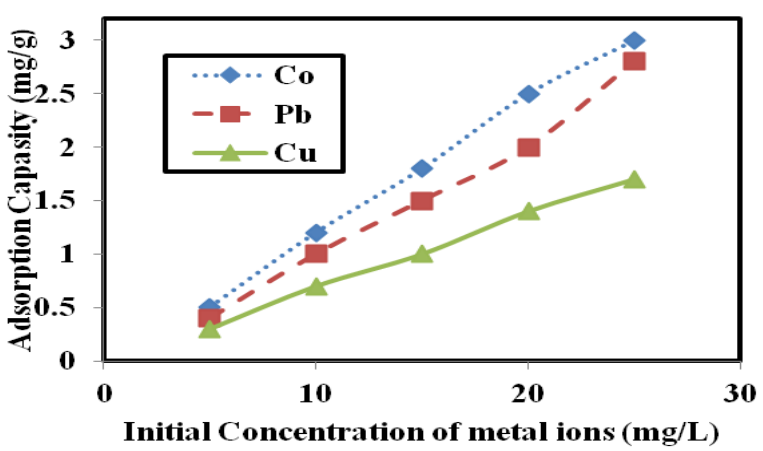

Figure 4: The effect of the metal ions initial concentration on the equilibrium adsorption capacity at $50^{\circ} \mathrm{C}$.

Table 2: The initial concentration of heavy metal ions with the adsorption capacity $(\mathrm{q})$ of $\mathrm{Co}, \mathrm{Pb}$, and $\mathrm{Cu}$ at 50 ${ }^{\circ} \mathrm{C}$

\begin{tabular}{|c|c|c|c|}
\hline $\begin{array}{c}\text { Initial } \\
\text { concentration of } \\
\text { heavy metals } \\
\text { ions }(\mathrm{mg} / \mathrm{L})\end{array}$ & $\begin{array}{c}\text { Adsorption } \\
\text { capacity of } \\
\mathrm{Co} \\
q(\mathrm{mg} / \mathrm{g})\end{array}$ & $\begin{array}{c}\text { Adsorption } \\
\text { capacity of } \\
\mathrm{Pb} \\
q(\mathrm{mg} / \mathrm{g})\end{array}$ & $\begin{array}{c}\text { Adsorption } \\
\text { capacity of } \\
\mathrm{Cu} \\
q(\mathrm{mg} / \mathrm{g})\end{array}$ \\
\hline 5 & 0.5 & 0.4 & 0.3 \\
\hline 10 & 1.2 & 1.0 & 0.7 \\
\hline 15 & 1.8 & 1.5 & 1.0 \\
\hline 20 & 2.4 & 2.0 & 1.4 \\
\hline 25 & 3.0 & 2.8 & 1.7 \\
\hline
\end{tabular}

\section{Conclusions}

In this study the removal of elements from Al- Dora refinery by using MWCNTs at different temperatures was investigated. The MWCNTs show exceptional adsorption 


\section{International Journal of Science and Research (IJSR) \\ ISSN (Online): 2319-7064}

Index Copernicus Value (2013): 6.14 | Impact Factor (2014): 5.611

capability for heavy metal ions removal such as of $\mathrm{Co}, \mathrm{Pb}$, and $\mathrm{Cu}$ from waste water of Al- Dora refinery after oxidized with nitric acid. Also, the adsorption capacity for $\mathrm{Pb}$ and $\mathrm{Cu}$ were 2.8 and $1.7 \mathrm{mg} / \mathrm{g}$, respectively. On the other hand, the high removal for oil content, THM, COD, and TSS by CNTs at $50{ }^{\circ} \mathrm{C}$ had been observed. It has been shown that activation of the MWCNTs with $\mathrm{HNO}_{3}$ an enhanced adsorption capacity for heavy metal ions and may offer a better solution for the removal of organic pollutants in water. These results suggest that MWCNTs have great potential applications in environmental protection. Nanotechnologies have made great improvements for handling water contamination problems and will clearly make further advancements in future. Nanotechnology based treatment has offered very effective, efficient, durable and eco friendly approaches.

\section{References}

[1] Masciangioli, T. and Zhang, W. X., Environmental technologies at the nanoscale. Environ. Sci. Technol. 37 (2003) 102-108.

[2] Prachi, P. G., Deepa, M., and Brijesh, A. N., Nanotechnology in Waste Water Treatment: A Review Nair, International Journal of ChemTech Research, 5 (2013) 2303-2308.

[3] Jia, G., Wang, H., Yan, L., Wang, X., Pei, R., Yan, T., Zhao, Y., and Guo, X., Cytotoxicity of carbon nanomaterials: single-wall nanotube, multi-wall nanotube, and fullerene. Environ. Sci. Technol., 39 (2005) 1378-1383.

[4] Crane, R. A., and Scott, T. B., Nanoscale zero-valent iron: Future prospects for an emerging water treatment technology. J. Hazard Mater, (2012), 211-212.

[5] Herrmann, J. M., Heterogeneous photocatalysis: fundamentals and applications to the removal of various types of aqueous pollutants. Catal. Today, 53 (1999) $115-129$.

[6] Hyung, N. H., Fortner, J. D., Hughes, J.B., and Kim, J. H., Natural organic matter stabilizes carbon nanotubes in the aqueous phase. Environ. Sci. Technol., 41 (2007) 179.

[7] Yang, K., Zhu, L., and Xing, B., Adsorption of polycyclic aromatic hydrocarbons by carbon nanomaterials. Environ. Sci. Technol. 40 (2006) 1855.

[8] Maddox, M. W., Gubbins, K. E., Molecular simulation of adsorption in buckytubes. Langmuir, 11 (1995) 3988.

[9] Iijima, S., Helical microtubules of graphic carbon. Nature, 354 (1991) 56.

[10]Long, R. Q., Yang, R. T., and Am, J., Carbon nanotubes as superior sorbent for dioxin removal. Chem. Soc., 123(2001) 2058.

[11]Lu, C., Chiu, H., Adsorption of zinc (II) from water with purified carbon nanotubes. Chem. Eng. Sci., 61(2006) 1138.

[12]Li, Y. H., Wang, S., Luan, Z., Ding, J., Xu, C., Wu, D. Lead adsorption on carbon nanotubes, Chemical Physics Letters, 357 (2002) 263.

[13] Stafiej, A., and Pyrzynska, K., Adsorption of heavy metal ions with carbon nanotubes, Separation and Purification Technology, 58 (2007) 49.
[14]Lu, C., Chung, Y., and Chang, K., Adsorption of trihalomethanes from water with carbon nanotubes. Water Res., 39 (2005) 1183.

[15]Li, Y. H., Wang, S., Luan, Z., Ding, J., Xu, C., and Wu, D., Adsorption of cadmium (II) from aqueous solution by surface oxidized carbon nanotubes, Carbon 41 (2003) 1057-1062.

[16]Chen, C., and Wang, X., Adsorption of Ni(II) from aqueous solution using oxidized multiwall carbon nanotubes, Ind. Eng. Chem. Res. 45 (2006) 9144-9149.

[17] Anirudhan T. S., Sreekumari S. S., Adsorptive removal of heavy metal ions from industrial effluents using activated carbon derived from waste coconut buttons, Journal of Environmental Sciences (2011), 23(12) 19891998

\section{Author Profile}

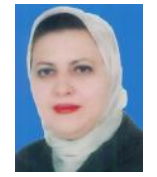

Hind Ibraheem Abdulgafour received the B.Sc degree in Physics from Baghdad University, Iraq in 1988, and Msc degree in Materials Physics from Baghdad University, Iraq in 1999. She worked at Iraq Atomic Energy Commission from 1988 to 2003. She was a chief of physicists at Ministry Of Science And Technology since 2004. She was got a patent titled (Preparation Of Wax Polymer Mixtures And A Study Of Physical Properties For These Materials ) from Iraq in 2001. She received her PhD degree in 2013 from the Universiti sains Malaysia. Currently, she is a researcher Ministry of Science and Technology in field (synthesis of $\mathrm{ZnO}$ nanostructures for sensing applications). She has published 26 papers in international and national journals and proceedings. 